\title{
LytM Fusion with SH3b-Like Domain Expands Its Activity to Physiological Conditions
}

\author{
Elzbieta Jagielska, Olga Chojnacka, and Izabela Sabała
}

Staphylococcus aureus remains one of the most common and at the same time the most dangerous bacteria. The spreading antibiotic resistance calls for intensification of research on staphylococcal physiology and development of new strategies for combating this threatening pathogen. We have engineered new chimeric enzymes comprising the enzymatically active domain (EAD) of autolysin LytM from $S$. aureus and the cell wall binding domain (CBD) from bacteriocin lysostaphin. They display potent activity in extended environmental conditions. Our results exemplify the possibility of exploring autolytic enzymes in engineering lysins with desired features. Moreover, they suggest a possible mechanism of autolysin physiological activity regulation by local ionic environments in the cell wall.

\section{Introduction}

$S$ TAPHYLOCOCCUS AUREUS IS an important cause of serious community and healthcare-acquired infections worldwide. These Gram-positive bacteria are responsible for a number of skin, soft tissue, and bloodstream infections, as well as endocarditis, meningitis, and bovine mastitis in dairy herds. ${ }^{1,2}$ The incidence rate of bacteremia caused by $S$. aureus is estimated to reach even 50 cases per 100,000 population every year and mortality rate between $10 \%$ and $30 \%$. $^{3}$ In UK alone, more than 10,000 cases of $S$. aureus bacteremia are reported each year with an associated mortality of about $30 \% .^{4}$ The clinical impact of infections has been amplified by the emergence and rapid spread of antibiotic-resistant strains, becoming a top priority for global health organizations and motivating a search for next-generation antibacterial agents.

Peptidoglycan (PGN) hydrolases, enzymes that catalytically degrade PGN of the bacterial cell walls, represent an interesting alternative to conventional antibiotics. ${ }^{5}$ These enzymes can be classified into several groups based on their origin, like autolysins (e.g., LytM), exolysins (lysostaphin), and endolysins, the latter utilized mostly by bacteriophages to allow their release from infected host cells at the end of the lytic cycle. ${ }^{6}$ They are also able to lyse the cells when added externally, making them potential antimicrobials. ${ }^{7}$

PGN hydrolases attach to the cell wall and degrade the PGN by cleavage of specific bonds. Most of them display modular structure of at least two distinct domains: one or more N-terminal enzymatically active domains (EAD) and C-terminal cell wall binding domain (CBD), which correspond to enzymatic and substrate recognition functions, respectively. ${ }^{8}$ The relative position and the number of the domains may vary. Domains are connected by a short flexible linker. ${ }^{9}$ In most cases, they can work independently and therefore are easy to be shuffled from different origins to engineer chimeric lysins with completely new features, like binding specificity, spectrum of activity, stability, solubility etc. $6,10-14$

PGNs are built of glycan and peptide moieties with composition and structure characteristic for each bacterial genera/species/strain. ${ }^{15}$ Gram-positive bacteria contain a very thick and highly cross-linked PGN layer, additionally decorated with carbohydrates and proteins. There are examples of enzymes for cleavage of each PG bond type and therefore various activities are found among enzymatically active domains of PGN hydrolases, like muramidases, glucosamidases, amidases, endopeptidases, and carboxypeptidases. ${ }^{16}$ CBD domains comprise a structurally and biochemically diverse group. One of the first CBD domains identified were the Cpl-7 domain of the pneumococcal amidase autolysin ${ }^{17}$ and Cpl-7-like CBD in group B streptococcal $\lambda$ Sa2phage endolysin. ${ }^{18}$ However, the best studied PG hydrolase CBDs are domains classified as $\mathrm{SH} 3 \mathrm{~b}$, a prokaryotic homologue of the eukaryotic src homology 3 (SH3) domains. ${ }^{12,19}$

The function of the SH3 domains is not well understood, but they may be involved in numerous processes such as increasing local concentration of proteins, altering their subcellular location and mediating the assembly of large multiprotein complexes. ${ }^{20} \mathrm{SH} 3$ domains in eukaryotic proteins are involved in signal transduction and binding of proline-rich

(C) Elzbieta Jagielska et al., 2016; Published by Mary Ann Liebert, Inc. This Open Access article is distributed under the terms of the Creative Commons Attribution Noncommercial License (http://creativecommons.org/licenses/by-nc/4.0/) which permits any noncommercial use, distribution, and reproduction in any medium, provided the original author(s) and the source are credited. 
protein sequences. ${ }^{21}$ A homologue of the $\mathrm{SH} 3$ domain has been found in many proteins of phage and bacterial origin, including glycylglycine endopeptidase (lysostaphin), phage endolysins, autolysins, and some hypothetical proteins. ${ }^{12}$

Three crystal structures of bacterial SH3 domains have been solved so far. ${ }^{22-24}$ The lysostaphin SH3b domain binds to pentaglycine interpeptide bridges of the $S$. aureus $\mathrm{PGNs}^{25}$ and is highly similar in amino acid sequence ( $>80 \%$ identity) and structure to Staphylococcus capitis ALE-1 endopeptidase. $^{22}$ Detailed information about how exactly $\mathrm{SH} 3 \mathrm{~b}$ domain interacts with PGNs is still not available as the structure of such domain with the substrates has not been published so far. Nevertheless, many chimeric lysines with SH3b domains have been recently engineered showing improved features, like affinity or specificity. ${ }^{11,26}$

In contrast to bacteriocins or bacteriophage endolysins, autolysins have not been explored so intensively as potential antibacterial agents. They are involved in autolysis, PGN recycling, cell division, and biofilm formation throughout normal bacterial cell lifecycle. ${ }^{27-29}$ One of the postulated barriers to therapeutic use of autolysins is their precise regulation by expression, localization, and catalytic activity control. ${ }^{30}$

One of the best characterized $S$. aureus autolysin is LytM, $\mathrm{Zn}^{2+}$-dependent glycylglycine endopeptidase, ${ }^{31-34}$ with a characteristic $\mathrm{HxH}$ motif that belongs to the MEROPS M23 family of metallopeptidases. ${ }^{35}$ Full-length LytM protein remains inactive against purified PGNs or live $S$. aureus and only truncated enzyme (residues 185-316, Fig. 1), which lacks the N-terminal fragment and the occluding region, shows a high lytic activity. ${ }^{34}$ The C-terminal region of LytM (LytM enzymatically active domain, LytM_EAD) has high similarity to the lysostaphin enzymatically active domain, Lss_EAD (52\% amino acid identity over 106 residues). Both enzymes are well characterized not only biochemically but also structurally. ${ }^{24,34,36,37}$

The enzymatic activity comparison of mature lysostaphin (Lss) and enzymatically active domain of LytM (LytM_EAD) has revealed a huge difference in their preferences

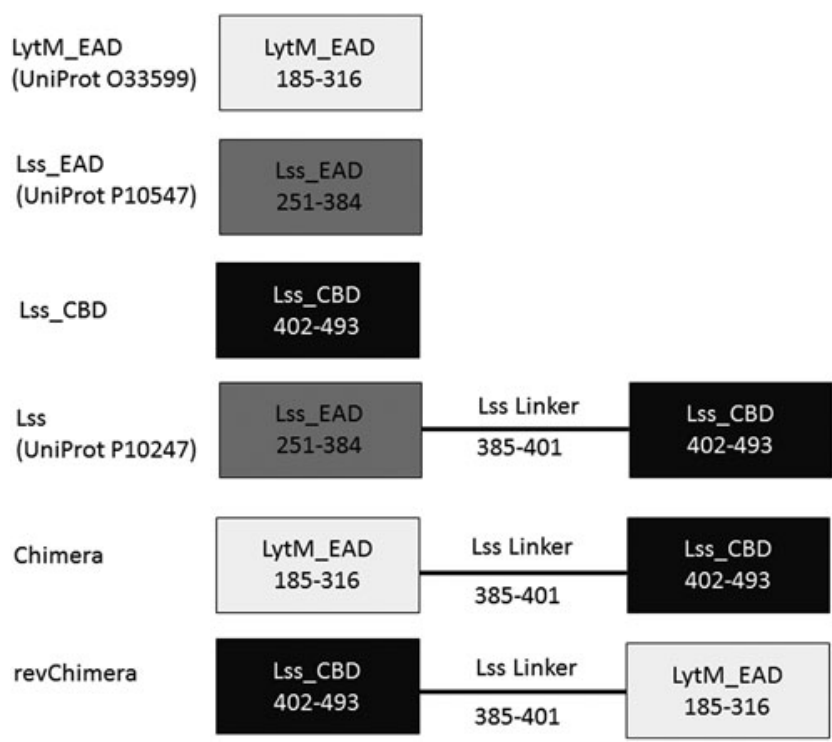

FIG. 1. Lysin constructs. Numbers in boxes represent amino acid positions in full-length proteins according to UniProt. for optimal ionic conditions. While lysostaphin degrades $S$. aureus cell walls very efficiently in buffers of higher ionic strength, LytM_EAD works best in very low conductivity buffers (up to $3 \mathrm{mS} / \mathrm{cm}$ ). ${ }^{33}$

While the main differences observed in activities of mature lysostaphin and LytM_EAD are their opposite preferences for ionic milieu of the reaction, the main structural difference is the lack of cell binding domain (CBD) in the latter one. We have engineered chimeric lysins consisting of N-terminal enzymatically active domain of LytM fused with lysostaphin cell wall binding domain (Lss_CBD) by lysostaphin linker sequence. In this study, we present the comparative analysis of chimeras and their parental enzymes and discuss the mechanism of CBD function in the regulation of enzymes activity.

\section{Materials and Methods}

\section{Bacterial strains}

Staphylococcus aureus MRSA clinical isolates were collected at Warsaw Medical University (Warsaw, Poland) and together with other staphylococcal reference strains were grown routinely in the Trypticase soy broth (TSB; SigmaAldrich) medium at $37^{\circ} \mathrm{C}$. Escherichia coli, Bacillus subtilis, and Pseudomonas aeruginosa reference strains were grown in the LB (Sigma-Aldrich) medium at $37^{\circ} \mathrm{C}$.

\section{Cloning and expression}

The enzymatically active domain of LytM (residues 185316), enzymatically active domain of lysostaphin (Lss_EAD, residues 251-384), mature lysostaphin (Lss residue 251-493), and lysostaphin cell wall binding domain (Lss_CBD) were cloned into an expression plasmid (pET15b, NcoI and XhoI restriction sites) under the control of the $\mathrm{T} 7$ promoter and lac repressor. LytM_EAD, Lss linker, and Lss_CBD domains in Chimera and revChimera were ligated using overlap extension polymerase chain reaction (PCR). ${ }^{38}$ Primers with $5^{\prime}$ overhang sequence complement to the end of the other DNA molecule, which will be ligated with, allowed to anneal two DNA fragments and multiply them by PCR reaction using another pair of prime complement to the target DNA ends. Such PCR products were purified and digested with $N c o I$ and XhoI enzymes and ligated with similarly digested $\mathrm{pET} 15 \mathrm{~b}$ expression vector.

E. coli TOP10 strain was transformed and after sequence verification, plasmids were transformed into BL21(DE3) E. coli strain. Overexpression of proteins was induced by $1 \mathrm{mM}$ IPTG and performed for about $4 \mathrm{hr}$ at $25^{\circ} \mathrm{C}$.

\section{Mutagenesis}

Chimera and revChimera linker double mutants were generated by PCR-based site-directed mutagenesis with Phusion high-fidelity DNA polymerase (Thermo Fisher Scientific) using pET15b-Chimera/revChimera plasmids as a PCR template. The presence of appropriate mutations was confirmed by DNA sequencing.

\section{Protein purification}

E. coli cell pellet containing overexpressed enzymatically active domain of lysostaphin (Lss_EAD), enzymatically active domain of LytM (LytM_EAD), mature lysostaphin (Lss), 
or lysostaphin cell wall binding domain (Lss_CBD) was suspended in $20 \mathrm{mM}$ Tris-HCl, $\mathrm{pH} 7.0,1 \mathrm{M} \mathrm{NaCl}$, and $10 \%$ glycerol $(50 \mathrm{mM} \mathrm{NaCl}$ for LytM_EAD) and disrupted by Constant Cell Disruption System (Constant Systems Ltd.). Cell lysate was dialyzed against $20 \mathrm{mM}$ Tris- $\mathrm{HCl}, \mathrm{pH} 7.0$, $50 \mathrm{mM} \mathrm{NaCl}$, and purified by exchange chromatography in $\mathrm{NaCl}$ gradient (SP Sepharose column; GE Healthcare). Further purification was done by gel filtration on Superdex 75 column (GE Healthcare) in $20 \mathrm{mM}$ Tris- $\mathrm{HCl}, \mathrm{pH} 7.0,200 \mathrm{mM}$ $\mathrm{NaCl}$, and $10 \%$ glycerol buffer. Overexpressed Chimera and revChimera enzymes were purified as described above with one exception; E. coli were lysed by sonication.

\section{Lytic assays}

Turbidity reduction assay. The turbidity assays were performed in 96-well microtiter plates. Bacterial cells used in all experiments were collected at exponential growth phase in TSB, washed, and suspended in an appropriate buffer to an apparent $\mathrm{OD}_{595}$ of 1.0. To each well, $100 \mu \mathrm{l}$ of bacterial suspension and $100 \mu \mathrm{l}$ of purified $200 \mathrm{nM}$ enzyme in an appropriate buffer were added. $\mathrm{OD}_{595}$ was monitored for $1 \mathrm{hr}$ at room temperature, with readings every $10 \mathrm{~min}$ and $5 \mathrm{sec}$ shaking. Tests were carried out in $1 \times$ phosphate-buffered

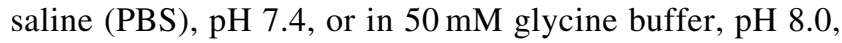
with or without additional $100 \mathrm{mM} \mathrm{NaCl}$.

Experiments at low temperature were carried out in $1 \mathrm{ml}$ volume on ice and measured as above in spectrophotometer. The lytic activity was calculated as a percentage of reduction of initial $\mathrm{OD}_{595}$. Each experiment was repeated thrice in triplicate.

$\mathrm{pH}$. The activity of LytM_EAD, chimeras, and mature lysostaphin was tested in the range of $\mathrm{pH}(5-9)$ using buffers of the same conductivity as $50 \mathrm{mM}$ glycine $\mathrm{pH} 8.0$ $(\sim 1 \mathrm{mS} / \mathrm{cm}): 10 \mathrm{mM}$ acetate-Na buffer $\mathrm{pH} 5.0,2 \mathrm{mM}$ citrate-Na buffer $\mathrm{pH} 6.0,5 \mathrm{mM}$ Tris- $\mathrm{HCl} \mathrm{pH} 7.0,10 \mathrm{mM}$ Tris- $\mathrm{HCl} \mathrm{pH} \mathrm{8.0,} \mathrm{and} 50 \mathrm{mM}$ Tris- $\mathrm{HCl} \mathrm{pH} \mathrm{9.0.} \mathrm{In} \mathrm{the} \mathrm{case} \mathrm{of}$ lysostaphin and chimeras, buffers were supplemented with $100 \mathrm{mM} \mathrm{NaCl}$.

SYTOX $^{\circledR}$ fluorescence assay. Fifty microliter of the reaction mixture containing $S$. aureus (grown to mid-log phase, washed twice in $1 \times \mathrm{PBS}$ or $50 \mathrm{mM}$ glycine, $\mathrm{pH} 8.0$ and suspended to the final $\mathrm{OD}_{595}=1.0$ ), $5 \mathrm{mM}$ SYTOX Green (Invitrogen), and enzymes. As the preliminary tests with $100 \mathrm{nM}$ concentration of enzymes show high sensitivity of the assay, the amount of enzymes was lowered to $10 \mathrm{nM}$ allowing better observation of differences between enzyme activities as well as more reproducible and reliable calculation of specific activity. Fluorescence intensity was measured for $1 \mathrm{hr}$ at room temperature using excitation of $504 \mathrm{~nm}$ and emission of $523 \mathrm{~nm}$. Mean fluorescence intensity was calculated from the steepest linear region of the lysis curve.

To evaluate statistical significance of the results, the twotailed Student's $t$-test (assuming equal variances in all samples) was used to calculate probabilities for the null hypothesis of equal means in pairwise comparisons.

\section{Minimal inhibitory concentration determination}

Minimal inhibitory concentrations (MICs) for LytM_EAD, Lss, and Chimera (G391A, G392A) were determined as previously described ${ }^{39}$ by growing $S$. aureus NCTC $8325-4$ in 96 -well plate $\left(4 \times 10^{5} \mathrm{CFU} / \mathrm{ml}\right)$ in $100 \mu \mathrm{l}$ of Mueller
Hinton II Broth (Sigma-Aldrich) supplemented with $2 \% \mathrm{NaCl}$ and $0.1 \%$ bovine serum albumin (BSA). Enzymes were added at concentrations ranged from 0.25 to $0.00025 \mu \mathrm{g} / \mathrm{ml}$ in twofold dilutions in the media. A positive control without added enzymes was included in each assay. Plates were incubated at $37^{\circ} \mathrm{C}$ with shaking $(150 \mathrm{rpm})$ for $24 \mathrm{hr}$. The absorbance using microplate reader was measured at $595 \mathrm{~nm}$ and MIC values determined based on wells with no measurable bacterial growth.

\section{CFU determination}

Turbidity reduction assays were performed as described above using $100 \mu \mathrm{l}$ of $S$. aureus NTCT 8325-4 from overnight culture grown in the Mueller-Hinton medium (SigmaAldrich) supplemented with $2 \% \mathrm{NaCl}$ and $0.1 \%$ BSA and $100 \mu \mathrm{l}$ of Lss, Chimera, or LytM_EAD diluted in the same medium to achieve final concentration of $100 \mathrm{nM}$ in the test. Reaction was incubated for $1 \mathrm{hr}$ at room temperature and both before and after the test, serial dilutions of reaction were plated on TSB-agar plates and left to grow overnight. The number of CFUs was counted next day. The experiment was performed thrice with five repeats each time.

\section{PGN binding assay}

The binding of proteins to $S$. aureus purified PGN experiments were performed as described previously. ${ }^{33}$ Ten microgram of each protein was incubated with purified PGN $\left(\mathrm{OD}_{595}=20\right)$ in $50 \mu \mathrm{l}$ of $50 \mathrm{mM}$ glycine buffer, $\mathrm{pH} 8.0$, with or without $100 \mathrm{mM} \mathrm{NaCl}$ at $4^{\circ} \mathrm{C}$ for $15 \mathrm{~min}$. Bound and unbound fractions of proteins were separated by centrifugation and analyzed on 15\% SDS-PAGE gels.

\section{Stability assays}

Purified proteins were stored at $-80^{\circ} \mathrm{C}$ in the storage buffer $(20 \mathrm{mM}$ Tris- $\mathrm{HCl} \mathrm{pH} 8.0,200 \mathrm{mM} \mathrm{NaCl}, 10 \%$ glycerol). For stability tests, the enzymes were diluted to the concentration of $1 \mathrm{mg} / \mathrm{ml}$ in the storage buffer and stored at $4^{\circ} \mathrm{C}$, and $37^{\circ} \mathrm{C}$ for up to 30 days. The integrity of proteins was checked on SDS-PAGE electrophoresis. The molecular weight of particular fragments of degraded proteins was determined by means of mass spectrometry on Synapt G2 instrument equipped with ESI source (Waters Corporation) at Warsaw University (Warsaw, Poland).

\section{Results and Discussion}

\section{LytM enzymatically active domain has greater bacteriolytic potential than lysostaphin enzymatically active domain}

Although mature lystostaphin (Lss) and LytM enzymatically active domain (LytM_EAD) have the same specificity and very similar antistaphylococcal activity, they require completely opposite conditions of ionic strength for their optimal performance. While the LytM_EAD activity is very high in low conductivity buffers $(<3 \mathrm{mS} / \mathrm{cm})$, mature lysostaphin shows high bacteriolytic efficiency only in high conductivity buffers $(>10 \mathrm{mS} / \mathrm{cm}) .{ }^{33}$

To further investigate this phenomenon, we have cloned, overexpressed, and characterized full-length lysostaphin (Lss), its enzymatically active domain (Lss_EAD), and the 
enzymatically active domain of LytM (LytM_EAD) (cloned domains are presented in Fig. 1). All proteins were produced in E.coli and purified to homogeneity. We have tested the activity of all enzymes in two different ways: by turbidity reduction assay and by measuring the kinetics of DNA release from lysed cell. While the turbidity reduction assay allows easy and simple monitoring of bacteriolytic efficiency of enzymes, fluorometric measurements of DNA release from lysed cells give a much more precise information on the specific activity and reaction kinetics.

The LytM_EAD activity is very limited in physiological conditions (PBS), ${ }^{33}$ however, in low conductivity environment (glycine buffer), LytM_EAD demonstrated great bacteriolytic potential (Fig. 2A). This effect was even more notorious when the fluorometric assay was used. The specific activity of LytM_EAD was the highest among all tested enzymes in the glycine buffer and the lowest in PBS (Fig. 2B). These assays confirmed previous observations of strong inhibition of LytM_EAD bacteriolytic activity by ions present in the reaction environment, ${ }^{33}$ which might implicate at least one of the mechanisms of LytM activity regulation in vivo.

In a similar way, the lysostaphin enzymatically active domain (Lss_EAD) showed slightly higher activity in glycine than in the PBS buffer. Nevertheless, LytM_EAD displayed twofold higher bacteriolytic and 10 times higher specific activity than Lss_EAD in the low conductivity buffer. These assays indicate that LytM_EAD possess much higher catalytic potential than the enzymatically active domain of lysostaphin.
A limited activity of isolated Lss_EAD was noticed previously. $^{40-42}$ Of note, it has been reported that the removal of the cell wall binding domain (CBD) from several phage endolysins completely abolished the activity of isolated enzymatically active domain. ${ }^{43,11}$

\section{Lysostaphin CBD domain enables LytM activity in high conductivity buffers}

In the low conductivity glycine buffer, both Lss and Lss_EAD showed similar activity, however, much lower than that detected for LytM_EAD. By contrast, the Lss activity was significantly higher than the activity shown by the enzymatically active domains, (Lss_EAD and LytM_EAD) in PBS $(p<0.001)$.

These results suggest that the presence of ions in the enzymatic reaction environment inhibits the activity of the catalytic domains, and it seems that the CBD helps to overcome this limitation since the mature lysostaphin showed a notorious activity under physiological conditions. The regulation of lysostaphin activity by $\mathrm{NaCl}$ has been noticed shortly after discovery of this enzyme, ${ }^{44,45}$ but it has never been properly investigated. Lu et al. reported inhibitory effect of $\mathrm{NaCl}$ on the activity of lysostaphin and its enzymatically active domain, but the effect on isolated domain was much stronger. ${ }^{41}$ Those experiments were carried out in a different range of ionic strength, so it is hard to discuss presented conclusions. However, we have never seen any inhibitory effects of increased ionic strength on the
FIG. 2. Specific activity of the lysins against Staphylococcus aureus NCTC 8325-4 reference strain. (A) Enzymes activities were observed as a turbidity reduction after $1 \mathrm{hr}$ in room temperature either in $1 \times \mathrm{PBS}$ or $50 \mathrm{mM}$ glycine buffer, $\mathrm{pH}$ 8.0. (B) Lytic activity of the enzymes was determined by SYTOX $^{\circledR}$ fluorescence assay performed in $1 \times \mathrm{PBS}$ or $50 \mathrm{mM}$ glycine buffer, $\mathrm{pH}$ 8.0 , at room temperature for $1 \mathrm{hr}$. PBS, phosphatebuffered saline.
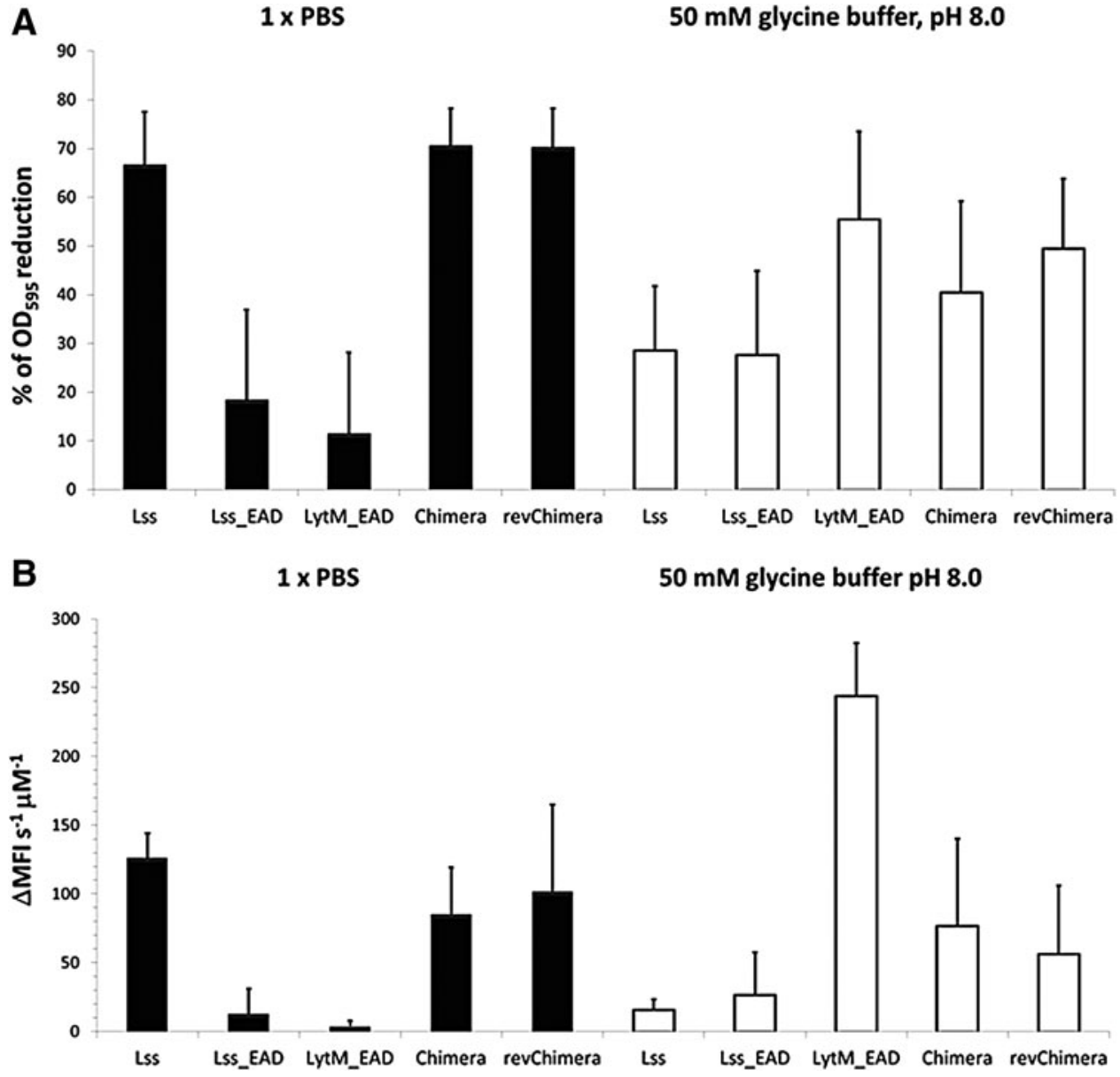
lysostaphin activity neither in experiments presented in this study nor in our previous reports. ${ }^{33}$

Becker et $a l .{ }^{11}$ reported a detailed analysis of activity of multidomain endolysin LysK variants comprising separate domains, modified linkers, or their combinations. Significant discrepancies between results of various activity assays were noticed; for example in the case of a separate CHAP domain, a very high activity was detected in zymography carried out in water, while no or very low activity was demonstrated in a turbidity reduction assay performed in a buffer with $150 \mathrm{mM} \mathrm{NaCl}$. This observation applies also to all other enzymes lacking CBD domain reported in the article and confirms the results of Horgan et al. who demonstrated high bacteriolytic activity of isolated LysK CHAP domain in both zymography and turbidity reduction assays, carried out in low conductivity conditions. ${ }^{46}$ This effect of enhanced binding affinity was reported also for other cell wall binding domains fused to enzymatically active domains, suggesting that this might be a more general rule. ${ }^{6,47}$

We have therefore assumed that the addition of lysostaphin cell wall binding domain (Lss_CBD) to the enzymatically active domain of LytM (LytM_EAD) will make its activity less dependent on ionic environment. Moreover, because of greater catalytic potential of LytM_EAD, such chimeric enzyme could exhibit greater bacteriolytic activity than lysostaphin itself.

To test this hypothesis, we have engineered two fusion lysins composed of LytM_EAD and Lss_CBD domains connected by 17 amino acid long lysostaphin linker. Those domains were ligated in both $\mathrm{C}$ - (Chimera) and N-terminal (revChimera) ends to test if Lss_CBD location has any impact on the lytic activity of fusion proteins (Fig. 1).

The bacteriolytic activity of generated chimeric lysins was tested in four different assays: turbidity reduction assay, fluorescence DNA release, MIC, and CFU determination, and compared to the activities of parental enzymes. Turbidity reduction and fluorescence DNA release assays showed that chimeras activity is as high as that of Lss in PBS, while in low conductivity conditions, chimeras performed better than Lss and Lss_EAD and only were slightly worse than LytM_EAD (Fig. 2).

High bacteriolytic efficiency of chimeras was confirmed by low MIC value of $0.125 \mu \mathrm{g} / \mathrm{ml}$, which is comparable to MIC values reported for lysostaphin ranging from 0.002 to $0.25{ }^{39,40}$ MIC values for LytM_EAD were not detectable because of high conductivity of the medium $(30 \mathrm{mS} / \mathrm{cm})$ in which the test has to be performed. Such conditions completely suppressed the activity of this enzyme (data not shown). Interestingly, MIC value for chimeric enzymes of identical architecture reported by Osipovitch was 2-10 times higher, ${ }^{40}$ which might be due to enhanced stability of our enzymes with introduced linker mutations (Supplementary Fig. S4A; Supplementary Data are available online at www.liebertpub.com/mdr).

CFU count seems to be the most precise and direct way to evaluate the efficiency of bacteriolytic enzymes. Although lysostaphin performed the best in our experiments reducing CFU from $1.62 \pm 0.21 \times 10^{9}$ to $4.00 \pm 3.00 \times 10^{5}$, chimera was able to reduce CFU by $3 \operatorname{logs}$ to $1.30 \pm 1.8 \times 10^{6}$, and LytM_EAD had no effect on CFU ending experiments with $1.81 \pm 1.08 \times 10^{9}$. This effect can be easily explained by the high conductivity of MHII media, in which the experiment was done much beyond values allowing LytM_EAD activity.
Difficulties in evaluation of bacteriolytic activity of endolysin and other bacteriolytic enzymes come from their multidomain structure and complexity of their substratescell walls, which are built of various components and comprise very different local environments. Various activity assays are being employed to characterize bacteriolytic and catalytic activity of PGN hydrolases. ${ }^{11,39,40}$ Even if similar assays are reported, the reactions are often carried out in different conditions making the comparison of the results very difficult, or even impossible. ${ }^{48}$

We have therefore concluded that addition of Lss_CBD domain to LytM_EAD increases its efficiency of bacteriolysis in physiological conditions. Moreover, the position of Lss_CBD domain (C- or N-terminal) has no influence on the overall antistaphylococcal activity of the fusion enzymes (Fig. 2A, B). Despite greater catalytic potential of LytM_EAD, generated chimeras did not perform better in our activity testes than lysostaphin. Still, they seem to have the greatest staphylolytic activity among autolysin-based chimeric enzymes. ${ }^{48}$

More systematic work would be needed to test whether regulation of lysin activity by ionic conditions is a more general phenomena and if this might be one of the mechanisms of controlling their physiological activity, particularly important for autolysins.

\section{PGN binding by chimeric lysins does not depend on ionic strength of the reaction environment}

This and previous studies indicate that the activity of multidomain enzymes depends on each of their components. The bacteriolytic potential of chimeric enzymes, composed of enzymatically active and cell wall binding domains, will be affected by two elements: the catalytic activity and the binding specificity/affinity of domains.

Analysis of lysostaphin structure ${ }^{24}$ suggests that there are no direct interactions between the two domains, which are joined with a flexible linker. Similar architecture is kept in our chimeras, therefore it is very likely that such statement will apply also to the interactions between LytM_EAD and Lss_CBD in engineered enzymes. If not by direct interactions between domains, then it must be another mechanism that allows explaining the higher activity of chimeric enzymes under high conductivity conditions. This could be the effect of the presence of $\mathrm{CBD}$ on binding of PGN by the enzymes. We tested this hypothesis by a binding assay in which Lss, LytM_EAD, and the chimeric lysin (Chimera) were used.

All the proteins bound $S$. aureus-isolated PGN under low ionic conditions, but under increased conductivity buffers, LytM_EAD was not able to bind the substrate and the binding was partially restrained also for Lss_EAD (Table 1 and Supplementary Fig. S1).

These results indicate that the addition of CBD to enzymatically active domain of LytM does not render its catalytic potential, but provides better binding to the substrate in higher ionic conditions. Although the general role of CBD is recognition and binding of the cell wall elements providing specificity of lysins, their impact on the regulation of activity and/or specificity of enzyme can be very diverse as reviewed by Schmelcher at al. ${ }^{49}$ While in some cases their presence is necessary for lysin activity, in others, isolated enzymatically active domains are more potent than their 
Table 1. Summary of Chimera Features Compared in Various Test and Assays With Their Parental Enzymes

\begin{tabular}{|c|c|c|c|c|c|c|c|c|c|c|c|c|c|c|}
\hline \multirow[b]{3}{*}{ Enzyme } & \multirow{2}{*}{\multicolumn{2}{|c|}{$\begin{array}{c}\begin{array}{c}\text { Turbidity } \\
\text { reduction } \\
\text { assay }\end{array} \\
\text { Conductivity }\end{array}$}} & \multirow{2}{*}{\multicolumn{2}{|c|}{$\begin{array}{c}\text { DNA realize } \\
\text { assay }\end{array}$}} & \multirow{2}{*}{\multicolumn{5}{|c|}{$p H$}} & \multirow{3}{*}{$\begin{array}{c}M I C \\
(\mu g / m l)\end{array}$} & \multirow{3}{*}{$\begin{array}{l}\text { CFU log } \\
\text { reduction } \\
\text { in high } \\
\text { conductivity }\end{array}$} & \multirow{3}{*}{$\begin{array}{c}\text { Activity } \\
\text { at } 0^{\circ} \mathrm{C} \\
\text { after } \\
30 \mathrm{~min}\end{array}$} & \multirow{2}{*}{\multicolumn{2}{|c|}{$\frac{\text { Binding assay }}{\text { Conductivity }}$}} \\
\hline & & & & & & & & & & & & & & \\
\hline & low & high & low & High & 5 & 6 & 7 & 8 & 9 & & & & low & high \\
\hline LytM_EAD & +++ & + & $* * * *$ & $*$ & + & + & ++ & +++ & + & ND & 0 & +++ & + & - \\
\hline Lss & ++ & +++ & $*$ & ** & ++ & ++ & +++ & +++ & +++ & 0.03 & 4 & + & + & + \\
\hline Lss_EAD & ++ & + & $*$ & $*$ & - & - & - & - & - & ND & 0 & + & + & \pm \\
\hline Lss_CBD & N/A & N/A & N/A & N/A & N/A & N/A & N/A & N/A & N/A & N/A & N/A & N/A & + & + \\
\hline Chimera & ++ & +++ & $* *$ & $* *$ & + & + & +++ & +++ & +++ & 0.125 & 3 & + & + & + \\
\hline revChimera & ++ & +++ & $*$ & $* *$ & ND & ND & ND & ND & ND & 0.125 & ND & ND & + & + \\
\hline
\end{tabular}

All assays were done as described in Materials and Methods section. ND, not determined; N/A, not applicable.

Reduction of initial turbidity (\%): + , up to $25 \%$; ++, 25-50\%; +++, 50-75\%; ++++, over $75 \%$.

Specific activity measured in DNA release assay $\left(\Delta \mathrm{MFIs}^{-1} \mu \mathrm{M}^{-1}\right)$ : *, up to $75 ; * *, 75-150 ; * * *, 150-225 ; * * * *, 225-300$

Binding assay: + , full binding; \pm , partial binding; - , no binding.

MFI, mean fluorescence intensity; MIC, minimal inhibitory concentration.

fusions with binding domains. Although we do not have experimental proof, we speculate that one of the possible reasons why not all catalytic potential is demonstrated in chimeric enzymes is a very tight or even irreversible attachment of CBD to bacterial cell walls, which limits accessibility of the substrate to the "immobilized" enzyme.

\section{Chimeric lysin activity versus parental proteins}

Specificity. One of the effects of fusing domains from various lysins is altered, usually extended specificity. LytM_EAD as well as Lss_CBD and its homologue from Staphylococcus capitis-EPK1, were reported to recognize and bind the same fragment of PGNs-pentaglycine crossbridges. $^{22,25,37}$ We have confirmed that the specificity of those domains in the newly generated fusion enzymes has not been changed and Chimera sustained their activity against Staphylococcus strains, including MRSA. The enzyme is not active against other Gram-positive and Gramnegative bacteria. LytM_EAD, lysostaphin, and Chimera activities were tested against three reference MSSA strains, three MRSA strains, and selected Gram-negative bacteria, namely Pseudomonas aeruginosa, Escherichia coli, and Bacillus subtilis (Fig. 3). Engineered Chimera appeared slightly more effective in lysing Staphylococcus strains than the original enzymes.

$\mathrm{pH}$. Although the optimal $\mathrm{pH}$ for the activity of lysostaphin and LytM_EAD is the same (7-8), the activity of Lss is sustained in a wider range of $\mathrm{pH}$. The same is true for chimeric enzymes, which expressed relatively high activity

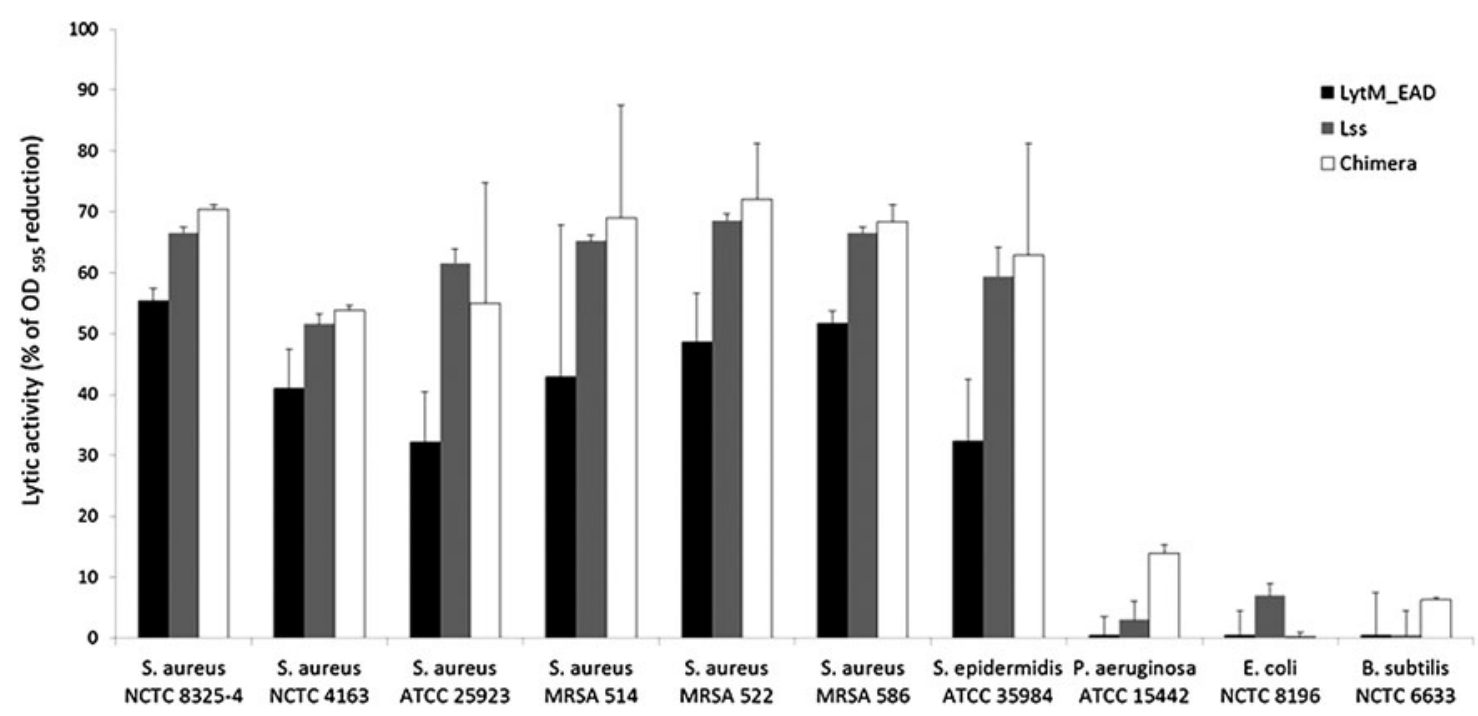

FIG. 3. Activity of the enzymes against various bacterial strains was measured as $\mathrm{OD}_{595}$ decrease of tested bacterial strains incubated $1 \mathrm{hr}$ in room temperature with $100 \mathrm{nM}$ enzymes in $50 \mathrm{mM}$ glycine buffer, pH 8.0 , additionally supplemented with $100 \mathrm{mM} \mathrm{NaCl}$ for Chimera and lysostaphin. 


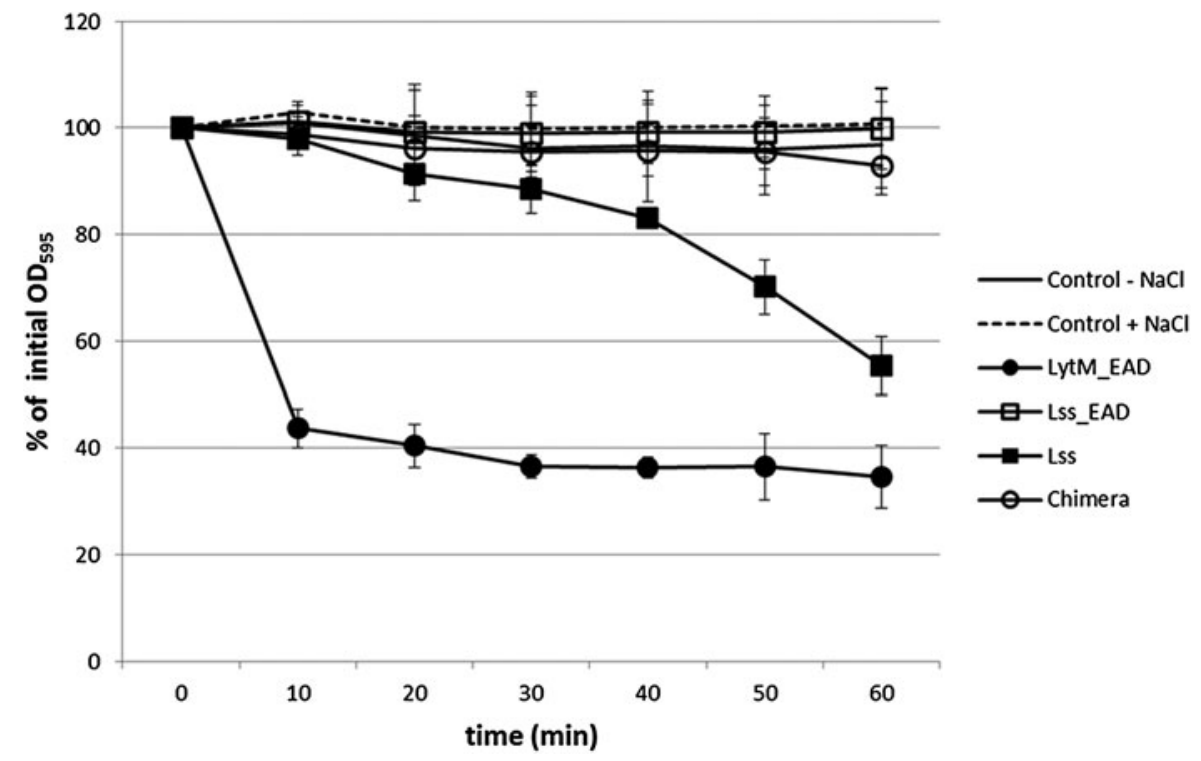

FIG. 4. Enzyme activity kinetics in low temperature. Studied enzymes were incubated with $S$. aureus NCTC 8325-4 reference strain in $50 \mathrm{mM}$ glycine buffer, $\mathrm{pH} 8.0$, supplemented with $100 \mathrm{mM} \mathrm{NaCl}$ (except for LytM_EAD) on ice for $1 \mathrm{hr}$ and their activity was observed as a turbidity reduction, $\mathrm{OD}_{595}$ was measured every $10 \mathrm{~min}$.

in a wider range of $\mathrm{pH}$ compared to parental enzymatically active domain of LytM. It looks that the presence of cell wall binding domain expands the range of $\mathrm{pH}$ permissible for LytM_EAD bacteriolysis (Supplementary Fig. S2).

Temperature. We have previously shown that, in contrast to lysostaphin, enzymatically active domain of LytM is able to lyse bacteria over a wide range of temperatures from $0^{\circ} \mathrm{C}$ to $45^{\circ} \mathrm{C}$. At $4{ }^{\circ} \mathrm{C}$, LytM_EAD is over four times more active than lysostaphin (European Patent No. 2699254). We have tested whether Chimera remains as active at $4^{\circ} \mathrm{C}$ as its parental LytM domain. Surprisingly, it turned out that the fusion of CBD domain with LytM_EAD strongly reduces the activity of chimeric enzyme at low temperature compared to LytM_EAD. Moreover, the chimeric enzyme was even less active than Lss (Fig. 4).

The exceptionally high lytic activity at low temperature is an unusual feature of LytM. There are only few examples of lysins with such a characteristic; for example, Zhang et $a l .{ }^{50}$ reported bacteriolytic phage endolysin LysZ5 effectively eliminating Listeria monocytogenes from milk at $4^{\circ} \mathrm{C}$. The high activity of LytM_EAD and lack of activity of our chimeric lysins at low temperature is puzzling and further investigations would be needed to reveal mechanisms of the observed results.

Stability. We have observed the degradation of recombinant Chimera and revChimera enzymes to two peptides after extended storage at $4^{\circ} \mathrm{C}$. Mass-spec analysis of these degradation products showed that both fusion lysins are cut at the lysostaphin linker site between two glycine residues G391 and G393 (Supplementary Fig. S3). This sequence was not recognized as a cutting site for any peptidase in PeptideCutter. $^{51}$ The fact that the cleavage occurred between two glycines, which shows some resemblance to the cutting site of LytM_EAD (pentapeptide sequence), lead us to speculate that this degradation might be the result of the residual activity of the chimeras.

To test this hypothesis, we have generated two single (G391A and G392S) and one double mutant (G391A, G392S) of our chimeric lysins (Supplementary Fig. S4A). Glycine residues are commonly found in linker sequences as they provide extra flexibility to the amino acid chain joining enzymatically active and cell wall binding domains. Replacement of two glycines in the linker sequence could have a negative effect on the enzyme activity due to increased stiffness of the linker between domains, which could lead to impaired bacteriolytic activity of chimeric enzymes. Fortunately, that was not the case as our mutants demonstrated full activity compared to parental chimeras (Supplementary Fig. S5). Stability tests showed that only double mutants of both Chimera and revChimera were much more stable than original fusion lysins. They can be stored at $4^{\circ} \mathrm{C}$ for at least one month without significant loss of stability and activity (Supplementary Fig. S4B).

We have generated a potent bacteriolytic autolysin-based chimeric enzyme by combining M23 domain of LytM and CBD of lysostaphin. We have demonstrated that the addition of the CBD to LytM_EAD expands the range of ionic and $\mathrm{pH}$ conditions supporting high activity of LytM enzymatically active domain. Moreover, we show that these phenomena might be explained not by improved catalytic activity but by enhanced PGN binding provided by the attached CBD. It would be interesting to further investigate if such "activation" of autolysins is more universal and may serve as yet another way of tight temporal and special regulation of the activity of this group of lysins.

\section{Acknowledgments}

The authors thank Dr. Adam Jagielski at Warsaw University (Poland) for mass-spec analysis of chimeric enzymes and Dr. Joanna Stefańska at Warsaw Medical University (Poland) for enzyme specificity measurement against various staphylococcus strains. The authors also thank Dr. Małgorzata Wiweger and Dr. Adam Jagielski for the thorough revision and discussion of the article. This work was supported by NCBiR grant (PBS1/A8/8/ 2012) (PL) and Foundation for Polish Science-SKILLS project: IMPULS competition cofinanced by the European Social Fund (87/UD/SKILLS/2014). 


\section{Disclosure Statement}

No competing financial interests exist.

\section{References}

1. Lowy, F.D. 1998. Staphylococcus aureus infections. N. Engl. J. Med. 339:520-532.

2. Gruet, P., P. Maincent, X. Berthelot, and V. Kaltsatos. 2001. Bovine mastitis and intramammary drug delivery: review and perspectives. Adv. Drug Delivery. Rev. 50:245-259.

3. van Hal, S.J., S.O. Jensen, V.L. Vaska, B.A. Espedido, D.L. Paterson, and I.B. Gosbell. 2012. Predictors of mortality in staphylococcus aureus bacteremia. Clin. Microbiol. Rev. 25: 362-386.

4. Thwaites, G.E., J.D. Edgeworth, E. Gkrania-Klotsas, A. Kirby, R. Tilley, M.E. Torok, S. Walker, H.F. Wertheim, P. Wilson, and M.J. Llewelyn. 2011. Clinical management of staphylococcus aureus bacteraemia. Lancet Infect. Dis. 11: 208-222.

5. Pastagia, M., R. Schuch, V.A. Fischetti, and D.B. Huang. 2013. Lysins: the arrival of pathogen-directed anti-infectives. J. Med. Microbiol. 62:1506-1516.

6. Nelson, D.C., M. Schmelcher, L. Rodriguez-Rubio, J. Klumpp, D.G. Pritchard, S. Dong, and D.M. Donovan. 2012. Endolysins as antimicrobials. Adv. Virus Res. 83:299-365.

7. Donovan, D.M. 2007. Bacteriophage and peptidoglycan degrading enzymes with antimicrobial applications. Recent Pat Biotechnol. 1:113-122.

8. Diaz, E., R. Lopez, and J.L. Garcia. 1990. Chimeric phagebacterial enzymes: a clue to the modular evolution of genes. Proc. Natl. Acad. Sci. U. S. A. 87:8125-8129.

9. Korndorfer, I.P., J. Danzer, M. Schmelcher, M. Zimmer, A. Skerra, and M.J. Loessner. 2006. The crystal structure of the bacteriophage PSA endolysin reveals a unique fold responsible for specific recognition of Listeria cell walls. J. Mol. Biol. 364:678-689.

10. Schmelcher, M., and M.J. Loessner. 2016. Bacteriophage endolysins: applications for food safety. Curr. Opin. Biotechnol. 37:76-87.

11. Becker, S.C., S. Swift, O. Korobova, N. Schischkova, P. Kopylov, D.M. Donovan, and I. Abaev. 2015. Lytic activity of the staphylolytic Twort phage endolysin CHAP domain is enhanced by the SH3b cell wall binding domain. FEMS Microbiol. Lett. 362:1-8.

12. Becker, S.C., J. Foster-Frey, A.J. Stodola, D. Anacker, and D.M. Donovan. 2009. Differentially conserved staphylococcal SH3b_5 cell wall binding domains confer increased staphylolytic and streptolytic activity to a streptococcal prophage endolysin domain. Gene. 443:32-41.

13. Fernandes, S., D. Proenca, C. Cantante, F.A. Silva, C. Leandro, S. Lourenco, C. Milheirico, H. de Lencastre, P. CavacoSilva, M. Pimentel, et al. 2012. Novel chimerical endolysins with broad antimicrobial activity against methicillin-resistant Staphylococcus aureus. Microb. Drug Resist. 18:333-343.

14. Mao, J., M. Schmelcher, W.J. Harty, J. Foster-Frey, and D.M. Donovan. 2013. Chimeric Ply187 endolysin kills Staphylococcus aureus more effectively than the parental enzyme. FEMS Microbiol. Lett. 342:30-36.

15. Schleifer, K.H., and O. Kandler. 1972. Peptidoglycan types of bacterial cell walls and their taxonomic implications. Bacteriol. Rev. 36:407-477.

16. Vollmer, W., B. Joris, P. Charlier, and S. Foster. 2008. Bacterial peptidoglycan (murein) hydrolases. FEMS Microbiol. Rev. 32:259-286.
17. Garcia, P., J.L. Garcia, E. Garcia, J.M. Sanchez-Puelles, and R. Lopez. 1990. Modular organization of the lytic enzymes of Streptococcus pneumoniae and its bacteriophages. Gene. 86:81-88.

18. Pritchard, D.G., S. Dong, M.C. Kirk, R.T. Cartee, and J.R. Baker. 2007. LambdaSa1 and LambdaSa2 prophage lysins of Streptococcus agalactiae. Appl. Environ. Microbiol. 73: $7150-7154$.

19. Ponting, C.P., L. Aravind, J. Schultz, P. Bork, and E.V. Koonin. 1999. Eukaryotic signalling domain homologues in archaea and bacteria. Ancient ancestry and horizontal gene transfer. J. Mol. Biol. 289:729-745.

20. Morton, C.J., and I.D. Campbell. 1994. SH3 domains. Molecular "Velcro". Curr. Biol. 4:615-617.

21. Harrison, S.C. 2003. Variation on an Src-like theme. Cell. 112:737-740.

22. Lu, J.Z., T. Fujiwara, H. Komatsuzawa, M. Sugai, and J. Sakon. 2006. Cell wall-targeting domain of glycylglycine endopeptidase distinguishes among peptidoglycan crossbridges. J. Biol. Chem. 281:549-558.

23. Marino, M., M. Banerjee, R. Jonquieres, P. Cossart, and P. Ghosh. 2002. GW domains of the Listeria monocytogenes invasion protein InlB are SH3-like and mediate binding to host ligands. EMBO J. 21:5623-5634.

24. Sabala, I., E. Jagielska, P.T. Bardelang, H. Czapinska, S.O. Dahms, J.A. Sharpe, R. James, M.E. Than, N.R. Thomas, and M. Bochtler. 2014. Crystal structure of the antimicrobial peptidase lysostaphin from Staphylococcus simulans. FEBS J. 281:4112-4122.

25. Grundling, A., and O. Schneewind. 2006. Cross-linked peptidoglycan mediates lysostaphin binding to the cell wall envelope of Staphylococcus aureus. J. Bacteriol. 188:24632472.

26. Idelevich, E.A., C. von Eiff, A.W. Friedrich, D. Iannelli, G. Xia, G. Peters, A. Peschel, I. Wanninger, and K. Becker. 2011. In vitro activity against Staphylococcus aureus of a novel antimicrobial agent, PRF-119, a recombinant chimeric bacteriophage endolysin. Antimicrob. Agents Chemother. 55:4416-4419.

27. Takahashi, J., H. Komatsuzawa, S. Yamada, T. Nishida, H. Labischinski, T. Fujiwara, M. Ohara, J. Yamagishi, and M. Sugai. 2002. Molecular characterization of an atl null mutant of Staphylococcus aureus. Microbiol. Immunol. 46: 601-612.

28. Kajimura, J., T. Fujiwara, S. Yamada, Y. Suzawa, T. Nishida, Y. Oyamada, I. Hayashi, J. Yamagishi, H. Komatsuzawa, and M. Sugai. 2005. Identification and molecular characterization of an $\mathrm{N}$-acetylmuramyl-L-alanine amidase Sle1 involved in cell separation of Staphylococcus aureus. Mol. Microbiol. 58:1087-1101.

29. Frankel, M.B., A.P. Hendrickx, D.M. Missiakas, and O. Schneewind. 2011. LytN, a murein hydrolase in the cross-wall compartment of Staphylococcus aureus, is involved in proper bacterial growth and envelope assembly. J. Biol. Chem. 286:32593-32605.

30. van Heijenoort, J. 2011. Peptidoglycan hydrolases of Escherichia coli. Microbiol Mol Biol Rev. 75:636-663.

31. Ramadurai, L., K.J. Lockwood, M.J. Nadakavukaren, and R.K. Jayaswal. 1999. Characterization of a chromosomally encoded glycylglycine endopeptidase of Staphylococcus aureus. Microbiology. 145 (Pt 4):801-808.

32. Ramadurai, L., and R.K. Jayaswal. 1997. Molecular cloning, sequencing, and expression of lytM, a unique autolytic gene of Staphylococcus aureus. J. Bacteriol. 179:3625-3631. 
33. Sabala, I., I.M. Jonsson, A. Tarkowski, and M. Bochtler. 2012. Anti-staphylococcal activities of lysostaphin and LytM catalytic domain. BMC Microbiol. 12:97.

34. Odintsov, S.G., I. Sabala, M. Marcyjaniak, and M. Bochtler. 2004. Latent LytM at 1.3A resolution. J. Mol. Biol. 335:775-785.

35. Rawlings, N.D., F.R. Morton, C.Y. Kok, J. Kong, and A.J. Barrett. 2008. MEROPS: the peptidase database. Nucleic Acids Res. 36:D320-D325.

36. Firczuk, M., A. Mucha, and M. Bochtler. 2005. Crystal structures of active LytM. J. Mol. Biol. 354:578-590.

37. Grabowska, M., E. Jagielska, H. Czapinska, M. Bochtler, and I. Sabala. 2015. High resolution structure of an M23 peptidase with a substrate analogue. Sci. Rep. 5:14833.

38. Bryksin, A.V., and I. Matsumura. 2010. Overlap extension PCR cloning: a simple and reliable way to create recombinant plasmids. BioTechniques. 48:463-465.

39. Kusuma, C.M., and J.F. Kokai-Kun. 2005. Comparison of four methods for determining lysostaphin susceptibility of various strains of Staphylococcus aureus. Antimicrob. Agents Chemother. 49:3256-3263.

40. Osipovitch, D.C., and K.E. Griswold. 2015. Fusion with a cell wall binding domain renders autolysin LytM a potent anti-Staphylococcus aureus agent. FEMS Microbiol. Lett. 362:1-7.

41. Lu, H.R., M.G. Gu, Q. Huang, J.J. Huang, W.Y. Lu, H. Lu, and Q.S. Huang. 2013. Hydrogen/deuterium exchange mass spectrometry and site-directed disulfide cross-linking suggest an important dynamic interface between the two lysostaphin domains. Antimicrob. Agents Chemother. 57: 1872-1881.

42. Bardelang, P., M. Vankemmelbeke, Y. Zhang, H. Jarvis, E. Antoniadou, S. Rochette, N.R. Thomas, C.N. Penfold, and R. James. 2009. Design of a polypeptide FRET substrate that facilitates study of the antimicrobial protease lysostaphin. Biochem. J. 418:615-624.

43. Loessner, M.J., G. Wendlinger, and S. Scherer. 1995. Heterogeneous endolysins in Listeria monocytogenes bacteriophages: a new class of enzymes and evidence for conserved holin genes within the siphoviral lysis cassettes. Mol. Microbiol. 16:1231-1241.
44. Schindler, C.A., and V.T. Schuhardt. 1965. Purification and properties of lysostaphin-a lytic agent for Staphylococcus aureus. Biochim. Biophys. Acta. 97:242-250.

45. Schindler, C.A. 1965. The role of $\mathrm{NaC} 1$ in the lysis of Staphylococcus aureus by lysostaphin. J. General Microbiol. 40:199-205.

46. Horgan, M., G. O’Flynn, J. Garry, J. Cooney, A. Coffey, G.F. Fitzgerald, R.P. Ross, and O. McAuliffe. 2009. Phage lysin LysK can be truncated to its CHAP domain and retain lytic activity against live antibiotic-resistant staphylococci. Appl. Environ. Microbiol. 75:872-874.

47. Schmelcher, M., V.S. Tchang, and M.J. Loessner. 2011. Domain shuffling and module engineering of Listeria phage endolysins for enhanced lytic activity and binding affinity. Microb. Biotechnol. 4:651-662.

48. Osipovitch, D.C., S. Therrien, and K.E. Griswold. 2015. Discovery of novel $S$. aureus autolysins and molecular engineering to enhance bacteriolytic activity. Appl. Microbiol. Biotechnol. 99:6315-6326.

49. Schmelcher, M., D.M. Donovan, and M.J. Loessner. 2012. Bacteriophage endolysins as novel antimicrobials. Future Microbiol. 7:1147-1171.

50. Zhang, H., H. Bao, C. Billington, J.A. Hudson, and R. Wang. 2012. Isolation and lytic activity of the Listeria bacteriophage endolysin LysZ5 against Listeria monocytogenes in soya milk. Food Microbiol. 31:133-136.

51. Gasteiger, E.H.C., A. Gattiker, S. Duvaud, M.R. Wilkins, R.D. Appel, and A. Bairoch. 2005. Protein identification and analysis tools on the ExPASy server. In John M. Walker (ed.), The proteomics protocols handbook. Humana Press Inc., Totowa, NJ, pp. 571-607.

Address correspondence to: Izabela Sabata, PhD International Institute of Molecular and Cell Biology in Warsaw Ks. Trojdena 4 Warsaw 02-109 Poland E-mail: izabela@iimcb.gov.pl 